\title{
Novas tecnologias e a história da cultura escrita. Obra, leitura, memória e apagamento
}

\section{New technologies and the history of written culture. Book, reading, memory and erasure}

https://doi.org/10.34112/2317-0972a2017v35n71p17-29

\section{Roger Chartien ${ }^{1}$}

Resumo: Este artigo foi apresentado como conferência no III Colóquio de Pesquisa Educação e História Cultural: Leituras da História e da Cultura, realizado na UNICAMP, entre 13 e 15 de junho de 2016. Nessa discussão foram propostas três perspectivas: uma reflexão sobre as características essenciais das novas tecnologias e suas diferenças com relação às formas herdadas da cultura escrita; a análise das mutações do ler e escrever no mundo digital, tanto na escola como fora dela; e, finalmente, algumas reflexões sobre a relação entre memória e apagamento, entre a proliferação dos discursos e sua "rarefação", como escreveu Foucault.

Palavras-chave: Novas tecnologias; História da Cultura Escrita; livro.

ABSTRACT: This article was presented as a lecture at the III Colóquio de Pesquisa Educação e História Cultural: Leituras da História e da Cultura, held at UNICAMP, between June 13 and 15, 2016. Three perspectives were proposed in this discussion: a reflection on the essential characteristics of new technologies and how they differ from the inherited forms of written culture; the analysis of the mutations of reading and writing in the digital world, both at school and abroad; and finally, some reflections on the relation between memory

1. Collège de France, Paris, França. 
and erasure, between the proliferation of discourses and their "rarefaction", as considered by Michel Foucault.

KEYWORDS: New technologies; History of Written Culture; book.

Neste trabalho quero propor três perspectivas: em primeiro lugar, uma reflexão sobre as características essenciais das novas tecnologias e suas diferenças com as formas herdadas da cultura escrita; em seguida, a análise das mutações do ler e escrever no mundo digital, tanto na escola como fora dela; e, finalmente, algumas reflexões sobre a relação entre memória e apagamento, entre a proliferação dos discursos e sua "rarefação", como escreveu Foucault (2006, p. 26).

Deve-se enfatizar, em primeiro lugar, que a revolução digital modificou tudo de uma vez: os suportes da escrita, as técnicas de sua reprodução e disseminação, e as maneiras de ler. Tal simultaneidade é inédita na história da humanidade. A invenção da imprensa não alterou as estruturas fundamentais do livro, composto, tanto antes como depois de Gutenberg, por folhas e páginas reunidos em um mesmo objeto. Nos primeiros momentos da era cristã, uma nova forma do livro, a do códex, se impôs e se substituiu no rolo ou volumen, mas não foi acompanhada de uma transformação da técnica de reprodução dos textos, sempre assegurada pela cópia manuscrita. E, por mais que a leitura tenha conhecido várias revoluções, identificadas ou discutidas pelos historiadores, todas ocorreram durante a longa duração do códex: assim, as conquistas medievais da leitura silenciosa e visual, a paixão por ler que caracterizou o tempo das Luzes, ou a partir do século XIX, a entrada, na leitura, dos recém-chegados: os meios populares, as mulheres e as crianças, tanto dentro como fora da escola.

Não quero repetir o que já escrevi sobre este tema, mas só enfatizar as mudanças introduzidas pela revolução do texto digital. A mais essencial se refere à ordem dos discursos. Na cultura impressa tal como a conhecemos, essa ordem se estabelece a partir da relação entre tipos de objetos (o livro, o diário, a revista), categorias de textos e formas de leitura ou uso. Semelhante vinculação está enraizada numa história de longa duração da cultura escrita e resulta da sedimentação de três inovações fundamentais: em primeiro lugar, entre os séculos II e IV, a difusão de um novo tipo de livro, que é ainda o nosso, ou seja, o livro composto de folhas e páginas reunidas dentro de uma mesma encadernação que chamamos códex e que substituiu os rolos da Antiguidade grega e romana; em segundo lugar, no final da Idade Média, antes da invenção da imprensa, nos séculos XIV e XV, o aparecimento do "livro unitário", quer dizer, a presença, dentro de um mesmo livro manuscrito, de 
obras compostas em língua vulgar por um só autor (Petrarca, Boccacio, Christine de Pisan), ainda que essa relação caracterizasse anteriormente somente as autoridades canônicas antigas e cristãs e as obras em latim; e, finalmente, no século XV, a invenção da imprensa, que continua sendo até agora a técnica mais utilizada para a produção de livros. Somos herdeiros dessa história, tanto para a definição do livro, que é ao mesmo tempo um objeto material e uma obra intelectual ou estética, um opus mechanicum e um discurso, como escreveu Kant, como para a percepção da cultura escrita, que está baseada em distinções imediatas entre diferentes objetos (cartas, documentos, diários, revistas, livros).

Ao romper o antigo laço entre o texto e o objeto, entre cada discurso e sua materialidade própria, a revolução digital obriga a uma radical revisão dos gestos e das noções que associamos à escrita. Apesar da inércia do vocabulário, que procura domesticar a novidade, denominando-a com palavras familiares (página, livro, imprimir), os fragmentos de textos que aparecem nas telas não são páginas, mas, sim, composições singulares e efêmeras. E, contrariamente a seus antecessores, rolo ou códex, o livro eletrônico não se diferencia das outras produções da escrita pela evidência de sua forma material.

Apoiado nessas mudanças, o mundo digital pode dar realidade aos sonhos, nunca alcançados, que o precederam. Da mesma forma que a biblioteca de Alexandria, promete a disponibilidade universal de todos os textos que foram escritos, de todos os livros que foram publicados. Como as práticas dos humanistas renascentistas, o mundo digital outorga a colaboração do leitor, que pode escrever ele mesmo no texto aberto e na biblioteca sem muros dos escritos eletrônicos. Como o projeto dos filósofos das Luzes, define um espaço público em que, como desejou Kant, cada indivíduo pode e deve fazer, sem restrições nem exclusões, um uso público da sua razão e comunicar por escrito suas opiniões. Nesse sentido, o mundo digital é muito mais que uma nova técnica de composição, transmissão e apropriação da escrita. Certamente, permite a digitalização dos textos já escritos, a produção de textos nascidos como digitais ou práticas de escrituras inéditas, tal com as dos blogs e redes sociais. Porém, impõe também a transformação das categorias mais fundamentais da experiência humana, por exemplo, as noções da amizade multiplicada até o infinito ou da identidade ou intimidade, ocultas ou exibidas, e também a invenção de novas formas de cidadania - ou de controle e de censura.

Como na época da invenção da imprensa, porém de maneira mais intensa, nosso presente digital está atravessado por tensões entre diferentes futuros possíveis: a 
multiplicação de comunidades separadas, cimentadas pelos usos específicos das novas técnicas; a apropriação, por parte das empresas mais poderosas - Google, Amazon -, do controle sobre a constituição e a difusão das bases de dados ou da produção e circulação da informação, ou mesmo da constituição de um público universal definido pela participação de cada um de seus membros na construção coletiva dos conhecimentos ou do intercâmbio de ideias, discursos e sentimentos. A comunicação a distância, livre, gratuita e imediata que a rede permite pode dar realidade a qualquer dessas virtualidades.

Assim, a grande conversão digital do presente pode levar à perda de toda referência comum, à separação radical das identidades, à exacerbação dos particularismos. Ao contrário, pode impor a hegemonia de um modelo cultural único, de uma língua dominante, e a destruição mutiladora das diversidades. Mas também pode produzir uma nova modalidade de construção e comunicação do saber, fundamentada no intercâmbio de conhecimentos, experiências e sabedorias. A nova navegação enciclopédica, se permite que cada um embarque em suas naves, poderia tornar plenamente realidade a esperança de universalidade que sempre acompanhou os esforços para envolver a multiplicidade das coisas e das palavras na ordem dos discursos.

O sonho da biblioteca universal parece hoje mais próximo de tornar-se realidade do que nunca esteve, mais ainda do que na Alexandria dos Ptolomeus. A conversão digital das coleções existentes promete a construção de uma biblioteca sem muros, onde se poderia acessar todas as obras escritas ou publicadas em algum momento e todos os escritos que constituem o patrimônio da humanidade. A ambição é magnífica e, como escreve Borges, não sem ironia, sobre a sua Biblioteca de Babel: "quando se proclamou que a Biblioteca abrangia todos os livros, a primeira impressão foi de extravagante felicidade" (BORGES, 1996, p. 75). Porém, seguramente, a segunda impressão deve ser uma interrogação sobre o que implica essa violência exercida sobre os textos dados a ler em formas que não são mais aquelas em que se apresentavam para seus leitores do passado. De novo se poderia dizer que semelhante transformação encontrou precedentes. Foi no códex, e já não nos rolos de sua primeira circulação, que os leitores medievais e modernos se apropriaram das obras antigas - ou, ao menos, daquelas que puderam ou quiseram copiar. Seguramente. Entretanto, para compreender os significados que os leitores deram aos textos dos quais se apoderaram, é necessário proteger, conservar e compreender os objetos escritos que os transmitiram. A "felicidade extravagante" provocada pela biblioteca universal digital poderia tornar-se uma impotente amargura se se traduzisse pela relegação ou, pior ainda, pela destruição 
dos objetos impressos que alimentaram ao longo do tempo os pensamentos e os sonhos daqueles e daquelas que os leram. A ameaça não é universal, e os incunábulos não têm nada a temer, porém não ocorre o mesmo com as mais humildes e recentes publicações - por exemplo, os jornais.

Todas as questões do presente vinculam-se com essas incertezas. Como manter o conceito de propriedade literária, definido desde o século XVIII a partir de uma identidade perpétua da obra, identificável qualquer que seja sua forma de publicação, em um mundo onde os textos são móveis, maleáveis, abertos? Como reconhecer uma ordem do discurso que foi sempre uma ordem dos livros ou, para dizer melhor, uma ordem do escrito que associa estreitamente autoridade de saber e forma de publicação, quando as possibilidades técnicas permitem, sem controles nem prazos, colocar em circulação universal opiniões e conhecimentos, mas também erros e falsificações? Como preservar maneiras de ler que construam a significação a partir da coexistência de vários textos em um mesmo objeto (um livro, uma revista, um periódico), enquanto o novo modo de conservação e transmissão dos escritos impõe à leitura uma lógica analítica e enciclopédica, onde cada texto não tem outro contexto, além do proveniente de seu pertencimento a uma mesma temática?

Estas perguntas têm relevância particular para as gerações mais jovens que, ao menos nos meios sociais com recursos e nos países mais desenvolvidos, têm se iniciado na cultura escrita através das telas dos computadores. Nesse caso, uma prática da leitura muito imediata e naturalmente habituada à fragmentação dos textos de qualquer tipo se opõe diretamente às categorias forjadas no século XVIII para definir as obras escritas a partir da individualização de sua escrita, da originalidade da criação e da propriedade intelectual de seu autor. A aposta não é sem importância, pois pode levar tanto à introdução, na textualidade eletrônica, de alguns dispositivos capazes de perpetuar os critérios clássicos de identificação de obras como tal, em sua identidade e propriedade, quanto ao abandono desses critérios, para estabelecer uma nova maneira de compor e perceber a escrita como uma continuidade textual, sem dono ou copyright, na qual o leitor corta e reconstrói fragmentos móveis e maleáveis.

Devemos pensar que a descontinuidade existe, inclusive, nas aparentes continuidades. A leitura diante da tela é descontínua, segmentada, ligada mais ao fragmento que à totalidade. Não seria, talvez, por esse motivo, a herdeira direta das práticas permitidas e suscitadas pelo códex? E o códex que convidou a folhear os textos, apoiando-se em seus índices, ou mesmo a "saltos e cabriolas", à sauts et gambades, como dizia Montaigne. Foi o códex, e não o computador, que incitou a comparar 
diferentes passagens, como queria a leitura tipológica da Bíblia, que encontrava no Antigo Testamento prefigurações do Novo; ou a extrair e copiar citações e sentenças, dados particulares e verdades universais, assim como exigia a técnica humanista dos lugares comuns. Contudo, a similitude morfológica não deve levar ao engano. A descontinuidade e a fragmentação da leitura não têm o mesmo sentido quando estão acompanhadas da percepção da totalidade textual contida no objeto escrito, tal como propõe o códex, e quando a superfície luminosa da tela onde aparecem os fragmentos textuais não deixa ver imediatamente os limites e a coerência do corpus (livro, número de revista ou do jornal) de onde foram extraídos.

A descontextualização dos fragmentos e a continuidade textual que não diferencia mais os diversos discursos a partir de sua materialidade própria parecem contraditórias com os procedimentos tradicionais da leitura que supõem tanto a compreensão imediata, graças à sua forma de publicação do tipo de conhecimento que se pode esperar de um discurso, como a percepção das obras como obras, em sua identidade, totalidade e coerência.

A revolução digital não está sem riscos, como mostra a inquietante capacidade do mundo eletrônico em dar credibilidade às falsificações ou aos erros e em submeter a hierarquia dos conhecimentos à lógica econômica das mais poderosas empresas multimídia. Esses temores são justificados e devem inspirar possíveis dispositivos para limitar os efeitos inquietantes da revolução digital. Porém, não devem deixar esquecer outras realidades mais promissoras.

Ao mesmo tempo em que modifica as possibilidades do acesso ao conhecimento, a revolução digital transforma profundamente as modalidades das argumentações e os critérios ou recursos que podem mobilizar o leitor para aceitá-las ou rejeitá-las. Por um lado, a textualidade eletrônica permite desenvolver as argumentações ou demonstrações segundo uma lógica que já não é necessariamente linear nem dedutiva, tal como implica a inscrição de um texto sobre uma página, mas sim que pode ser aberta e relacional, graças à multiplicação dos vínculos hipertextuais. Por outro lado, e como consequência, o leitor pode comprovar a relevância de qualquer análise, consultando, por si mesmo, os textos (mas também as imagens, as palavras gravadas ou as composições musicais) que são o próprio objeto do estudo - naturalmente, se estiverem acessíveis em uma forma digital. Semelhante possibilidade transforma as técnicas clássicas da prova (notas de rodapé de página, citações, referências bibliográficas), que supunham que o leitor tivesse confiança no autor, sem ter a possibilidade de colocar-se na mesma posição que ele diante dos documentos 
analisados ou utilizados. Nesse sentido, a revolução digital constitui também uma mutação epistemológica que modifica os modos de construção e acreditação dos discursos do saber. Pode-se, assim, abrir novas perspectivas à aquisição de conhecimentos outorgada pela leitura como possibilidades inéditas pela ficção, como o mostram as obras digitais mencionadas no Electronic Literature Compilation.

Mesmo sem nos projetarmos em um futuro ainda incerto e desconhecido e concebendo o livro eletrônico em suas formas e seus suportes atuais, continua pendente uma questão: a da capacidade desse novo livro de encontrar ou produzir seus leitores. A longa história da leitura mostra que as mutações na ordem das práticas frequentemente são mais lentas que as revoluções das técnicas ou suportes. Novas maneiras de ler não se impuseram imediatamente depois da invenção da imprensa. Do mesmo modo, para os leitores adultos as categorias intelectuais que associamos ao mundo dos textos perduraram com as novas formas do livro eletrônico. Por um lado, resiste o livro impresso no mercado do livro. Salvo nos Estados Unidos e no Reino Unido, a percentagem dos livros digitais nas vendas de livros nunca supera $5 \%$. E, nos Estados Unidos, onde os livros eletrônicos representam 20\% do mercado do livro, suas vendas recuaram de $10 \%$ em 2014 e, de novo, em 2015. Por outro lado, todas as "instituições" da cultura impressa se encontram em estado de crise. Na Europa, livrarias desaparecem todo dia, em razão da concorrência dos supermercados ou da Amazon. Em todo o mundo os jornais têm grandes dificuldades econômicas e desaparecem. E as bibliotecas conhecem a tentação de privilegiar as coleções digitais e afastar os leitores dos objetos impressos.

No entanto, devemos menosprezar a originalidade do nosso presente: as diferentes revoluções da cultura escrita, que no passado estavam separadas, se apresentam hoje simultaneamente. Na verdade, a revolução do texto eletrônico é, ao mesmo tempo, uma revolução da técnica de produção e reprodução dos textos, uma revolução da materialidade e da forma de seu suporte e uma revolução das práticas de leitura. Substitui a proximidade física que vincula os vários textos copiados ou impressos em um mesmo livro (ou uma revista ou um periódico) por sua distribuição nas arquiteturas lógicas que governam os bancos de dados, as coleções digitais ou as publicações eletrônicas. Por outro lado, redefine a materialidade das obras, porque desata o laço visível que associa um texto e o objeto que o transmite e porque dá ao leitor, e não ao autor ou editor, o domínio sobre a forma e o formato das unidades textuais que queira ler. Assim, é todo o sistema de percepção e de uso dos textos que se encontra transformado. 
Essa observação nos conduz a refletir sobre o terceiro tema de nossa conferência: as relações entre memória e apagamento. Esta questão se enraíza numa série de tensões profundas que atravessam os séculos. A primeira opõe o poder desejado e o poder perigoso do livro. Impresso ou manuscrito, o escrito tem sido permanentemente investido com um poder ao mesmo tempo esperado e temido. É possível ler o fundamento de tal ambivalência no texto bíblico, com a menção do livro comido como aparece no Apocalipse de João, X, 10 : "E tomei o pequeno livro da mão do anjo e comi-o, e era doce na minha boca como o mel; e havendo o comido o meu ventre ficou amargo". O livro dado por Deus é amargo, como o conhecimento do pecado, e doce como a promessa de redenção. A Bíblia, que contém o livro da Revelação, foi ela mesma considerada como um livro poderoso, que protege e conjura, aparta as desgraças, afasta as maldições. Em toda Cristandade, o livro sagrado foi, assim, objeto de usos propiciatórios e protetores que não supunham necessariamente a leitura de seu texto, mas que exigiam sua presença material o mais próxima possível dos corpos.

O livro é, portanto, o depositário de conhecimentos poderosos, mas temíveis. Na Tempest, de Shakespeare, Caliban, que o sabe, pensa que o poder de Próspero será destruído, se forem capturados e queimados seus livros: "Burn but his books". Mas os livros de Próspero não são mais do que um único livro que lhe permite submeter à sua vontade a natureza e os seres. Esse poder demiúrgico representa uma terrível ameaça para quem o exerce. Para afastar o perigo, o livro deve desaparecer, afundado nas profundezas das águas: " $\mathrm{E}$, ao fundo do mar, onde nem a sonda chega,/Lançarei o meu livro'." [I'll drown my book] (SHAKESPEARE, 2001, p.72). Três séculos mais tarde, Borges (2001) nos ensina que é em outras profundidades, aquelas das prateleiras da Biblioteca Nacional na Rua México, em Buenos Aires, onde deveria ser sepultado um livro que, por ser de areia, não era menos inquietante. Assim, expressam-se de maneira contundente dois temores contraditórios que habitaram a Europa da primeira época moderna, e que todavia nos atormentam nos dias de hoje: por um lado, o medo ante a proliferação indomável dos escritos, a multiplicação de livros inúteis, a desordem do discurso; e, por outro, o medo da perda, da falta, do esquecimento. É uma tensão comparável que caracteriza os

2. Em inglês, o segundo verso é I'll drown my book, e o trecho poderia ser traduzido por "E aí onde jamais caiu a sonda/eu vou afundar o meu livro”. 
nossos tempos confrontados com os desafios de uma nova forma de inscrição e conservação dos textos na memória do computador.

Semelhante tensão entre a proliferação dos discursos e os procedimentos encarregados de assegurar sua "rarefação" se encontra no centro da conferência de Foucault (2006, p. 8-9), L'ordre du discours:

Eis a hipótese que gostaria de apresentar, para fixar o lugar - ou talvez o teatro muito provisório - do trabalho que faço: suponho que em toda sociedade a produção do discurso é ao mesmo tempo controlada, selecionada, organizada e redistribuída por certo número de procedimentos que têm por função conjurar seus poderes e perigos, dominar seu acontecimento aleatório, esquivar sua pesada e temível materialidade.

Para ele, os três tipos de procedimentos assegurando a rarefação dos discursos eram os sistemas de exclusão que definem as palavras proibidas, que separam loucura e razão e afirmam a vontade de verdade de certos discursos; os princípios de classificação, de ordenação e de distribuição dos discursos; e, finalmente, as regras que não permitem que todo mundo tenha acesso a alguns discursos.

Outra formulação da mesma tensão entre acumulação e rarefação, entre proliferação e apagamento se pode se encontrar também no conceito de "esquecimento de reserva”, oubli de réserve, que constitui um tema maior do livro de Paul Ricoeur, Mémoire, histoire, oubli, uma vez que o esquecimento é considerado como a condição de possibilidade da memória. O "esquecimento de recordação" é o "caráter desapercebido da perseverança da lembrança, seu escape à vigilância da consciência" (RICOEUR, 2007, p. 448 e 451). Evita que a memória seja paralisada pelas lembranças e fechada só na rememoração. $\mathrm{O}$ conceito é construído por Ricoeur, a partir de três referências.

Inicialmente, Ser e tempo, de Heidegger, de onde é extraída a citação fundamental que contém todo o raciocínio: "Da mesma forma que a expectativa só é possível se houver uma espera, a lembrança [Erinnerung] só é possível baseada num esquecimento, e não o contrário" (HEIDEGGER, 2012, citado por RICOEUR, 2007, p. 450).

Segunda referência: Funes el memorioso, em que Borges entrelaça dois motivos: o do esquecimento, como condição do pensamento, enquanto processo de abstração e de generalização ("Este, não o podemos esquecer, era quase incapaz de idéias gerais, platônicas") e o do esquecimento como condição do sono ("Para ele, dormir era muito difícil. Dormir é distrair-se do mundo”) (BORGES, 1996, p. 
107 e p. 108). Numa de suas inúmeras entrevistas, Borges (1992, p. 331-332) retoma as próprias condições da escrita de Funes el memorioso:

Um homem, comum e muito ignorante, tem uma memória perfeita, tão perfeita que as generalizações lhe são proibidas. Ele morre bem jovem, derrotado por essa memória, que um deus poderia suportar, mas não um homem. Seria o caso contrário: Funes não pode esquecer nada. Por conseguinte, ele não pode pensar, pois, para pensar, é preciso generalizar, ou seja, esquecer. [... ] O que pretendo dizer, com certeza, é que, nas últimas linhas, Funes morre. Morre sobrecarregado do peso de um passado minucioso demais para ser suportado. Um passado feito principalmente de circunstâncias, que normalmente são esquecidas. [... Não somente ele pode reconstituir tudo, mas é obrigado a fazê-lo, ou seja, não pode se livrar do peso do universo.

A opressão da memória impede tanto o sono como o pensamento, que supõem, um e outro, a capacidade de esquecer. Funes, ao contrário, associa uma extrema sensibilidade da percepção, incapaz de qualquer forma de abstração, e uma capacidade, sem limites, de acumular os saberes. Ele pode aprender tudo, as línguas, o mundo, o passado e, como declara: "Eu sozinho tenho mais lembranças que terão tido todos os homens desde que o mundo é mundo" (BORGES, 1996, p. 105). Mas aprender sem parar, ou se lembrar de tudo não é pensar, pois "pensar é esquecer diferenças, é generalizar, abstrair. No mundo entulhado de Funes, não havia senão detalhes, quase imediatos”. (BORGES, 1996, p. 108).

Funes, ou o homem que não esquecia, é um monstro, que inverte os julgamentos tradicionais. Enquanto, basicamente, a doença ou o acidente supostamente fazem perder a memória, é após uma queda, depois de ter se chocado contra "um cavalo meio selvagem", que Funes, "agora irremediavelmente enfermo", quase paralisado, adquire uma memória sem limites e sem falhas. Aliás, enquanto os casos de memória prodigiosa são tradicionalmente objeto da maior admiração, a memória absoluta de Funes é causa de sua infelicidade e o conduz à morte, na idade de 19 anos. Borges estabelece, assim, uma relação invertida entre a excelência das memórias excepcionais dos grandes homens do passado e essa outra, funesta, de seu pobre herói, fazendo do capítulo 24 do livro VII da Naturalis historia, de Plinio, dedicado à memória, uma das leituras de Funes, capaz de enumerar, em latim e espanhol, os casos de memória prodigiosa: Cyrus, Mithridate Eurapator, Simonide, 
Metrodorus. Os mesmos exemplos se encontram na compilação enciclopédica de Pedro Mexía, um dos livros utilizados por Cervantes em Don Quijote.

Freud é o terceiro ponto de apoio mobilizado por Ricœur para construir a noção de esquecimento de reserva. Aos dois textos, de 1914 e 1915, explicitamente citados por ele, podemos acrescentar um terceiro, publicado em Nota sobre o 'bloco mágico', um texto comentado por Derrida. O “bloco mágico” era, no final do século XIX em Viena, uma espécie de lousa mágica, ou seja, um objeto composto de uma prancha de cera ou de resina, sobre a qual era colocada uma placa de celuloide transparente e uma folha de papel encerado, translúcido. A escrita, traçada com um estilete, era apagada quando se puxava para baixo a placa de celuloide; e, assim, o bloco ficava disponível para uma nova escrita. Mas, como observa Freud (2011), se expusermos o bloco a uma luz apropriada, é possível decifrar os traços deixados por uma escrita, embora ela tenha sido apagada. O "bloco mágico" constituía, assim, para ele, uma analogia material da própria estrutura do aparelho psíquico, ao menos na conceptualização do tópico pré-consciente-consciente-inconsciente, porque, se o sistema percepção-consciência tem uma capacidade ilimitada de receber percepções, mas sem inscrição durável, o sistema mnésico conserva os seus traços duradouros, recuperáveis, mas situados no inconsciente. No Wunderblock os escritos são apagáveis e efêmeros, multiplicados de maneira ilimitada, mas as inscrições apagadas sobre ele podem ser decifradas, pelo menos parcialmente, para quem sabe procurá-las. Devemos aproveitar essas várias figuras filosóficas ou literárias do apagamento ou do esquecimento para compreender nosso presente dividido entre a acumulação sem perda dos saberes e conhecimentos, dos textos e das informações e, por outro lado, o gesto permanente do apagamento e a obsolescência dos arquivos digitais?

Como se sabe, a única competência dos historiadores, que sempre foram lamentáveis profetas, é recordar que, dentro da longa duração da cultura escrita, toda mudança (o aparecimento do códex, a invenção da imprensa, as várias revoluções da leitura) produziu uma coexistência original de objetos e práticas do passado com técnicas novas. Toda vez que tal mudança ocorreu, a cultura escrita conferiu novos papéis aos antigos objetos ou práticas: o rolo na era do códex, a publicação manuscrita na era da impressão, a leitura em voz alta no tempo da leitura silenciosa e visual. É uma tal reorganização da cultura escrita que a revolução digital faz imaginar, esperar ou desejar. Pode-se supor que, como no passado, os escritos serão redistribuídos entre os diferentes suportes (manuscritos, 
impressos, digitais) que permitem sua inscrição, sua publicação e sua transmissão. Resta, porém, o fato da dissociação das categorias - e até mesmo a contradição entre elas - que constituíram uma ordem do discurso fundamentada no nome do autor, na identidade das obras e na propriedade intelectual; e, de outro lado, o radical desafio a essas noções no mundo digital que promete a produção de obras móveis, maleáveis, abertas, multimídia, ao mesmo tempo palimpsesto e polifonia, libertados tanto da página quanto do copyright.

Podemos pensar e esperar com Umberto Eco e Jean-Claude Carrière um futuro no qual coexistiriam as várias culturas escritas. Mas acho que a verdadeira resposta não está nos hábitos e nos desejos dos leitores que entraram no mundo digital a partir de suas experiências como leitores de livros impressos. A resposta pertence aos digital natives, que identificam espontaneamente cultura escrita e textualidade eletrônica. São suas práticas da leitura e da escrita, mais do que nossos discursos, que vão decidir a sobrevivência ou a morte do livro, o apagamento do passado ou sua presença perpetuada.

\section{REFERÊNCIAS}

BORGES, J. L. “A Biblioteca de Babel” e "Funes o memorioso”. In: . Ficções. Tradução de

Davi Arrigucci Jr. São Paulo: Companhia das Letras, 1996. . Enquêtes suivi d'Entretiens avec Georges Charbonnier. Paris: Gallimard, 1992.

FOUCAULT, M. A ordem do discurso. Tradução de Laura Fraga de Almeira Sampais. 13. ed. São Paulo: Loyola, 2006.

FREUD, S. Nota sobre o 'bloco mágico' (1925). In: . Obras completas: O Eu e o Id, Autobiografia e Outros Textos. Tradução de Paulo César de Souza. São Paulo: Companhia das Letras, 2011. v. 16.

HEIDEGGER, M. Ser e tempo. Tradução de Fausto Castilho. Editora da Unicamp: Vozes, 2012. MONTAIGNE, M. Sobre a Vaidade. Tradução de Ivone C. Benedetti. São Paulo: Martins Fontes, 1998. RICOEUR, P. A memória, a história, o esquecimento. Tradução de Alain François et al. Campinas, SP: Editora da Unicamp, 2007.

SHAKESPEARE, W. A tempestade. Tradução de Fátima Vieira. Porto: Campo das Letras, 2001.

\section{SOBRE O AUTOR}

Roger Chartier é um reconhecido historiador francês, com uma vasta obra publicada. É docente na Collège de France (Paris, França), na cátedra Écrit et Cultures dans l'Europe Modern, da École des Hautes Études en Sciences Sociales 
(Faculdade de Altos Estudos em Ciências Sociais). Destaca-se no campo da História Cultural, com pesquisa e estudos importantes sobre a história da cultura e dos livros, a trajetória da leitura e da escrita como práticas sociais.

E-mail: chartier@ehess.fr.

Recebido em 31 de março de 2017 e aprovado em 26 de abril de 2017. 